\title{
Segmenting Excessive Alcohol Consumers: Implications for Social Marketing
}

\begin{abstract}
While extant studies have mainly investigated differences between drinkers and non-drinkers, the literature on segmenting heavy drinkers and profiling them is surprisingly scarce. This study makes a significant contribution to the social marketing literature by illustrating a novel way of targeting heavy drinkers by utilising their health management styles and provides useful insights into understanding how segmentation could be a valuable tool for developing effective social marketing programmes that are aimed at reducing excessive alcohol consumption. Analysis of data collected through the HINTS study reveals a twocluster segmentation model. The two segments of heavy drinkers distinctly differ in terms of the extent of reliance and trust they place on the health service professionals. Hence, the segmentation analysis provides interesting and novel insights into the level of dependence of heavy drinkers on the health care system and their health management styles. The study provides an actionable perspective for future research, public policy and social marketing.
\end{abstract}

Key words: segmentation, excessive alcohol consumption, social marketing, health management style, cluster analysis 
Excessive alcohol consumption is a major public health problem, especially in the West (Paswan et al. 2015; Nelson et al. 2009). According to the World Health Organization, 3 million people worldwide die of alcohol-related causes in 2018 (WHO, 2018). The U.S. Center for Disease Control and Prevention (CDC) claims that excessive alcohol consumption not only kills about 88,000 people in the United States alone each year, but also has a huge economic impact. The economic cost of excessive alcohol consumption in the United States increased to $\$ 249$ billion in 2010 from $\$ 223.5$ billion in 2006, which translates to a significant increase from $\$ 1.90$ per drink in 2006 to $\$ 2.05$ per drink in 2010 (cdc.gov). These costs were largely attributed to reduced workplace productivity, increased crime, and the burgeoning cost of treating people for health problems caused by excessive drinking. In UK about 7700 alcohol specific deaths occurred in 2017 and about 1.13 million hospital admissions that were alcohol related (NHS Digital, 2018). Because of the potential adverse consequences associated with excessive alcohol consumption, it is not surprising that it has been a hot topic in government policies and health care service research, especially social marketing (Hassan and Shiu, 2007; Hogan, Perks and Russel-Bennett, 2014; Kubacki et al. 2015; O’Cass and Griffin, 2015).

Social marketing is emerging as a popular tool for bringing about positive social change (O'Cass and Griffin, 2015) as it is now being increasingly acknowledged that effective interventions need to be market driven for eliciting meaningful change in behaviours (Rundle-Thiele et al. 2015). As "social marketing seeks to develop and integrate marketing concepts with other approaches to influence behaviours that benefit individuals and communities for the greater social good" (p.2215), it can play a key role in targeting long-term behaviour change (Kubacki et al. 2015). For example, social marketing has been shown to be effective in changing a variety of social and health behaviours such as encouraging blood donation (Masser et al., 2009), reducing obesity (Croker et al., 2012), reducing binge drinking (Hogan, Perks and Russel-Bennett; 2014 and improving healthy eating (Carins and Rundle-Thiele, 2013). To initiate positive social change in long-term behaviour, social marketing focuses on the target consumer and uses insights gained from consumers to develop the intervention planning process (French, 2009). As such, strategic planning is at the heart of social marketing. It is vital that social marketers fully understand the target consumers before planning any interventions aiming to achieve their behavioural change.

Extant research demonstrates that studies suggesting interventions aimed at reducing alcohol consumption have mostly focused on demographic profiles and have compared heavy 
drinkers with moderate or light drinkers and non-drinkers (Leeman et al. 2012; Neighbors et al. 2007; Johnston et al. 2005). However, given the tight budgets social marketers work with, social marketing efforts need to be primarily focused on heavy drinkers, given the enormous human social and economic toll on individuals and society. Assuming that all heavy drinkers have similar profiles with respect to demographics, psychographics, motivations or behaviour would be naïve (Kubacki et al. 2011). Therefore, to aid in effective planning of social marketing interventions, it is important to understand heavy drinkers in terms of the key characteristics of their different segments. While past studies have mostly used demographic and socio-psychological traits, surprisingly little research has evaluated the contribution of factors such as health management styles (see Perzynski et al. 2011) in understanding alcohol consumption. The present research addresses this key gap in the literature.

We develop clusters of heavy drinkers based on their demographics, psychological trait, health status and health management style. The main objective is to identify the different segments of heavy drinkers so that social marketing techniques could be employed according to their profiling characteristics. Understanding these key differences among excessive alcohol consumers is crucial for planning social marketing programmes aimed at reducing their alcohol consumption.

Although previous research has identified specific factors affecting alcohol consumption, literature indicates that more research is required to "determine how best to classify, label or identify" heavy drinkers to implement and tailor interventions toward these individuals (LaBrie et al. 2007; p. 90). For instance, a review of the literature indicates that, surprisingly, most studies on alcohol consumption do not employ market segmentation (Kubacki et al. 2015). Hence, a key limitation noted in many alcohol education programs is that "they are designed for a general population using a 1-size-fits-all approach" (Dietrich et al. 2015; p.252). Only a few studies have utilised demographics, behaviour or psychological traits (e.g. Hassan and Shiu, 2007; Glik et al. 2008; Moss, Kirby and Donodeo, 2009; Dietrich et al. 2015) as the bases of heavy drinker segmentation. In particular, no previous study could be found that has utilised psychographic segmentation based on health management styles to segment heavy drinkers for understanding their attitudes and behaviours. This is important as past research demonstrates that aspects of the patient-doctor relationship (Blixen et al., 2008; Vermeire et al., 2001; Sutton et al. 2015) play a key role in reducing alcohol consumption. For example, a recent study demonstrates that aspects of health management styles such as cooperation with doctors, living a healthy lifestyle and trust in doctors are significantly related to alcohol consumption (Perzynski et al. 2011). Thus, 
profiling clusters of heavy drinkers based on their health management style may offer meaningful interpretations regarding their attitudes and behaviours as heavy drinkers could have varied health management styles and thus may approach health care in different ways. Given the limited budgets that most social marketers work with along with an increasing emphasis on accountability (Rundle-Thiele et al. 2015), such profiling may help social marketers in designing marketing programs that specifically target those factors, which are likely to have the greatest impact on alcohol consumption among people belonging to a specific cluster. Moreover, as self-efficacy can predict psychological changes that can explain individual health and healthcare decisions (Bandura 1977), it is argued that self-efficacy is an important psychological trait that may influence alcohol consumption (Perzynski et al. 2011). Thus, the concept of self-efficacy is an important factor to consider while profiling segments of heavy drinkers as it may determine the extent to which one is likely to respond to social marketing efforts (O'Cass and Griffin, 2015). Accordingly, in this study, we develop clusters of heavy drinkers based on a combination of several psychographic variables (such as health management style, self-efficacy and health status) that have previously beenused in studies primarily for understanding adherence (DiMatteo, 2004). Such an approach may help to obtain a more comprehensive view of the profiles of heavy drinkers to better understand their attitudes and behaviours for developing social marketing interventions .

The paper is structured as follows. First we review the literature relating to segmentation and health management style. We then discuss the methodology and cluster analysis, which is followed by discussion and managerial implications.

\section{Segmenting Excessive Alcohol Consumers}

The social marketing literature suggests that distinct segments exist within target groups, and they have differential responses to social marketing programs (Gray \& Bean, 2011; Walsh, Hassan, Shiu, Andrews, \& Hastings, 2010). Segmentation in social marketing draws on behavioural and psychographic data to assist social marketers to target specific segments in the development of promotional and marketing campaigns so that the available resources could be directed to the most promising segments (Rundle-Thiele et al. 2015). This is essential as different segments may require different marketing styles and techniques to make a real difference and elicit positive social change. As such, segmentation can be an extremely powerful tool "to reduce marketing expenditures by avoiding mass marketing and instead, 
investing resources into those target markets which are most promising" (Dolnicar and Grun, 2017; p.105). For example, Moss Kirby and Donodeo (2009) used the PRIZM data base, a demographic profile based database, to identify consumer segments who are most prone to drinking, and discovered 10 segments of consumers who are prone to binge drinking. Barnett et al (2008) developed a three cluster solution in a study of young heavy drinkers. The cluster analysis used factors like responsibility, aversiveness and the number of heavy drinking days. Cooper (1994) identifies four primary clusters of reasons for drinking — social motives, conformity motives, enhancement, and coping motives, while Hassan and Shiu (2007) focus on gender differences. In another study (Dietrich et al. 2015), demographics, drinking attitudes, drinking intentions, and alcohol knowledge were cluster analyzed to identify segments. However, despite the well acknowledged significance of market segmentation, it is noted in a recent study that social marketers often do not report using segmentation in their interventions; segmentation needs to be encouraged among social marketers (Rundle-Thiele et al. 2015), especially with the objective of reducing alcohol consumption through social marketing efforts (Kubacki et al. 2015). In this respect, few studies have looked at classification of heavy drinkers using their attitude towards health care or level of reliance on health service providers. We feel this is an important consideration in the context of controlling heavy drinking as non-utilisation of medical facilities has been shown to be a major problem in treating alcohol addiction (Cohen et al, 2007). For instance, Cunningham and Breslin (2004) found, in their study among heavy drinkers in Canada, that only one in three heavy drinkers actually access any medical facilities, while Cohen et al's (2007) study shows that only $27 \%$ individuals with alcohol dependence and abuse problems actually utilise any medical treatment. We address this limitation in the literature by utilising health management style as the main basis of classification as explained below.

\section{The Segmentation Model}

Drawing on the Transtheoretical Model of Behavior Change (Prochaska and DiClemente, 1992) and the Theory of Reasoned Action (Fishbein and Yzer, 2003), Perzynski et al. (2011) developed and tested a conceptual model, which acknowledges the importance of patient knowledge, attitudes, belief systems, and coping strategies, and postulates that psychosocial states and traits (such as health management style and self-efficacy) influence alcohol consumption (Perzynski et al. 2011). As a person's own assessment of what he or she expects to do (intention) and confidence (self-efficacy) in his or her ability to do are key determinants 
of behaviour, (Fishbein and Yzer, 2003), both health management style and self-efficacy may be crucial in understanding alcohol consumption behaviours.

Health Management Style refers to the approach followed by individuals to manage their own health in terms of either seeking professional help from doctors or other health service professionals and / or relying on their own ability to regulate their health. Aspects of health management styles include reliance on doctors, cooperation with doctors, trust in doctors, and reliance on oneself to live a healthy lifestyle and caring for one's health (Fiscella et al., 1999; Millon et al., 1979; Perzynski et al. 2011). This construct therefore reflects an individual's overall attitude towards the health care system as well as the willingness to interact with health service providers. As prior literature suggests that patients' adherence is partially determined by aspects of the patient-doctor relationship (Blixen et al., 2008; Vermeire et al., 2001), health management style may be crucial to consider for reducing alcohol consumption.

Self-efficacy, which refers to "judgment of one's capability to accomplish a certain level of performance" (Bandura, 1986, p. 391) is another important factor in understanding alcohol consumption as it not only influences addictive behaviour, but also behaviour changes leading to abstinence (Paswan et al. 2015). Bandura (1977) proposed that selfefficacy can explain and predict psychological changes that influence healthcare decisions. Thus, the concept of self-efficacy may be important to understand the process an individual will go through in reducing alcohol intake and seeking medical care.

As individuals consider their health status when evaluating the pros and cons of drinking alcohol (Stoller et al., 2009), it is argued that health status can also influence health behavior decision-making (Perzynski et al. 2011) and thus may be an important factor to consider along with health management style and self-efficacy.

Accordingly, in this study we adopt the health management style as developed by Perzynski et al (2011) as the main basis for developing the segmentation schema for classifying heavy drinkers. Thus, variables that define the health management style of individuals are used as the basis for initial classification of heavy drinkers. Since an effective segmentation model includes factors that are used as the initial basis for classification as well as factors that are used for deeper profiling of the segments that emerge from the basic classification model to provide more information about each of the segments, hence, in order to gain a deeper understanding of the ensuing segment, two other classes of factors are used: (i) Health Status: This refers to health status of the heavy drinkers in terms of depression, anxiety, physical and/or other cognitive symptoms experienced by them 
(ii) Self-efficacy: This refers to the confidence that an individual has in his or her ability to manage one's own health.

\section{Methodology}

Data for this research was obtained from the U.S. Department of Health and Human Services, through the Health Information National Trends Survey (HINTS). This is a widely used and comprehensive survey, consisting of responses from over 7,600 individuals. The HINTS survey uses a representative sample from the population in the United States of America and is dedicated to learning how people find, use and understand health information (hints.cancer.gov). The HINTS survey collects information on an array of topics related to an individual's interactions with the health care facilities as well as general beliefs and attitudes on health care related issues. It provides a credible data base for understanding public perceptions and behaviour. This study used the data collected through the survey to identify heavy drinkers and their attitudes towards health care.

Heavy drinkers are defined as people who drink heavily and have a significantly increased risk of developing alcohol problems. Heavy drinking is defined using National Institute of Alcohol Abuse and Alcoholism (NIAAA, 2009) as:

- Women: More than seven drinks per week or three drinks per occasion

- Men: More than 14 drinks per week or four drinks per occasion

Based on this definition, sample elements who did not fall in the heavy-drinker category were excluded from the data base. In order to classify the total sample from the HINTS data base into heavy and non-heavy drinkers, questions about drinks consumed per day and per week were used in consonance. For females, all those who informed that they drank more than seven drinks per week were included in the heavy drinker category, while for males, only those who drank more than 14 drinks per week were included in the heavy drinker category. From the sample, a total of 431 heavy drinkers were identified. Of these, 153 respondents or $35 \%$ were males and 236 or 55\% were females. However, in the 431 respondents, 42 (9.7\%) did not specify their gender. We still retained them since all those whose gender was not clear, consumed at least 20 drinks per week and would safely fall in the heavy drinker category whether they were males or females. The male heavy drinkers in the group consumed on an average about 31 drinks per week and the female drinkers consumed on an average about 18 drinks per week. Of the heavy drinker sample, 294 respondents (68\%) were above 45 years of age, 74 respondents (17\%) were between 18 and 34 years of age and 58 respondents (13.5\%) were between 34 and 44 years of age. 


\section{Cluster Analysis}

In order to cluster the heavy drinkers based on their health management style, a two-step cluster analysis was carried out among the 431 heavy drinkers. In order to assess the health management style of individuals, seven questions from the HINTS study were used. These questions are provided in Table 2. These questions sought the opinion of the respondents about the quality of the interactions with their healthcare provider in the last 12 months. The questions amply covered issues related to attention, feelings, emotions, etc. The questions were answered through a four point scale anchored between 'Always =1; Usually =2; Sometimes $=3$ and Never $=4$ '. Answers to these questions revealed the extent to which an individual relied on their healthcare provider and the degree to which they cooperated with the health provider - issues directly related to the health management style of the individual. Individuals who gave the answer 'never' to the statements had never relied on their health provider for solving health related problems or never depended on health professionals. Individuals who answered 'always' to the set of statements were on the other hand were very dependent on the health professionals and therefore showed heavy reliance.

The two-step clustering method was chosen for clustering the problem drinkers to identify problem drinker segments (SPSS, 2001). The optimal number of clusters is determined by the Bayesian inference criterion (BIC), a model selection criterion proposed by Schwarz. It is calculated using the formula:

$$
\mathrm{BIC}_{i}=-2 \ln \left(L_{i}\right)+\mathrm{k}_{i} \ln (n)
$$

where $n$ is the sample size; $\mathrm{k}_{i}$ is the number of parameters in model $i$; and $\ln \left(L_{i}\right)$ is the maximized value of the likelihood function for the estimated model $i$. The results of the auto clustering process, are shown in Table 1; indicating that the two cluster solution was the most appropriate as it had the largest ratios of both BIC changes and distance measures.

Insert Table 1 here

Details of the two cluster solution in terms of the composition is provided in Table 2. The number in a particular cell indicates the number of respondents who marked that particular response to the statement and were categorised into that particular cluster. As is quite clear from the table, most of the members of Cluster.1 have marked 'always', 'usually' or 'sometimes' to the statements while most of the members in Cluster.2 have marked 'never' to the statements. The cluster solution thus divides the heavy drinkers into: (i) a group comprising 177 sample elements or roughly $42 \%$ of the population who feel that they 'usually' or 'always' get good health related advice and support from the health providers and 
thus perceive the health care quality received to be adequate, and (ii) a group comprising roughly $58 \%$ of sample who feel they 'never' get good health related advice and support.

Cluster.1 therefore comprises heavy drinkers who are highly reliant on health service professionals and have high levels of trust on health service professionals. Cluster. 2 on the other hand comprises heavy drinkers who feel they have 'never' received any support and are therefore prone to completely ignore the healthcare system. In the ensuing sections, we try to look at whether this segmentation system makes sense in explaining other patterns in the heavy drinker groups to potentially guide meaningful policy development. We first start with correlating the profiles of individuals with the segments.

\section{Profiling Excessive Alcohol Consumers and Cluster Membership}

The two heavy drinker clusters were first analysed in terms of any significant patterns in age or gender. The gender and age related analysis is provided in Table 3. Pearson's chi-square test used to assess the relationship between age profile, gender profile and cluster membership did not yield any significant result (for gender chi-square $=0.00$, d.f $=1 ; \mathrm{p}<0.9$; for age chi-square $=8.99$, d.f $=4 ; \mathrm{p}<0.1$ ) and hence it can be concluded that there is no relationship between age and cluster membership. This shows that heavy-drinkers from any age group or any gender have roughly the same probability to fall into any of the two clusters. Similarly, analysis of the cluster membership across education level and family income also did not produce any significant Pearson chi-square coefficient (for education level chi-square $=5.99$, d.f $=4, \mathrm{p}<0.01$; for family income level chi-square $=3.2$, d.f $=4, \mathrm{p}<0.1$ ). This goes to show that the two groups of heavy drinkers could come from any demographic profile.

-Insert Tables 2 and 3 here

To further understand the profiles of the two clusters, differences between the alcohol intake across the two clusters were assessed. A one-way ANOVA shows the F-value to be insignificant $(\mathrm{F}=0.13, \mathrm{p}<0.1)$, which implies no difference between the groups of the heavy drinking clusters in terms of the alcohol intake.

\section{Cluster membership and related attitudes and beliefs}

In order to build a profile of each segment, other beliefs and attitudes related to the perception of quality of health care are analysed. In the first instance, the correlation between cluster membership and the perceived difficulty in receiving health related information as well as the level of trust placed by the respondent to information from different sources was 
assessed. Answers to three questions from the HINTS questionnaire were found to be correlated. These questions were:

"The information you found was hard to understand"

(ii) "Overall how confident are you that you could get advice from or information about health or medical topics if you need it?"

(iii) "Overall how would you rate the quality of health care you received in the past 12 months"

Response to the first question was obtained on a four-point scale anchored between 'Strongly agree' and 'Strongly disagree'. Lower scores for these questions indicate difficulty in obtaining and comprehending information. The response to the second question was assessed through a five-point scale anchored between 'completely confident' to 'not confident at all' where a high score indicated that the respondent was not confident of getting the information. The response to the third question was assessed through a five-point scale anchored between 'excellent' to 'poor' with lower values indicating high levels of satisfaction.

To assess the level of trust, answers to a question that asked the respondents to rate the extent to which they trust information about health and medical topics from different sources of information were correlated with the cluster membership. The extent of trust was measured through a four point scale ranging from 'Not at all' to 'A lot'. While the extent of trust from a range of sources like 'doctors', 'family or friends', 'Newspapers or magazines', 'radio', 'Internet' etc. were assessed, only the level of trust with information from 'doctors' and 'family' members correlated with the cluster membership. This shows that there is no difference between different clusters on the extent to which they trust information from impersonal external sources like 'radio', 'internet' etc. Table. 4 shows the ANOVA results as well as the mean values.

Insert Table 4 here

The analysis in Table 4 demonstrates that heavy drinkers clusters based on the perceived quality of health care also differ in their belief about accessing information on healthcare as well as trust derived from different sources of health care information. In general, members of Cluster.1 - who have a higher dependence on health care services, also feel the highest difficulty in retrieving health care information. Cluster.1 members are found to be significantly more satisfied with the quality of the health care as compared to members of Cluster 2. Members of Cluster.1 also significantly trust their doctors as well as their own families or friends to a greater degree than members of Cluster.2. 
In the next stage, the heavy-drinker cluster membership was correlated with overall level of depression or anxiety in their lives. Responses to these questions provide a broad indication to how the individual feels about his/her life, health etc. Results of this analysis are provided in Table.5.

Insert Table 5 here

Statements reflecting these constructs were anchored on a four point scale ranging from 'nearly every day' to 'not at all'. Analysis of the cluster means indicate that Cluster.1 members had lower values across the four statements such as lack of interest (statement.1), hopelessness (statement.2), nervousness (statement.3) and worry (statement.4). Thus, it is seen that members from Cluster.1, who have high dependence on doctors and medical professionals also seem to be very depressed, worrying, nervous and hopeless. On the other hand, Cluster.2 members who are characterised by relatively less dependency on doctors or health service professionals, have the least levels of worry or hopelessness.

In order to assess the differences between groups for overall opinion of their health, ANOVA was run for the single question "In general would you say your health is" anchored between 'Excellent' to 'Poor' with lower values indicating better health condition. The analysis produced a significant $\mathrm{F}$-value $(\mathrm{F}=14.17, \mathrm{p}<0.00)$. Interestingly members of Cluster. 1 had the lowest estimation of their health condition as compared to Cluster. 2 members.

\section{Interpreting the clusters}

Analysis of the demographic profile of heavy-drinker segments as well as the significant attitude/opinion variables help to build a clearer understanding of the clusters. Of course, there is little correlation between age and income with the two clusters and hence, it is assumed that the two clusters are formed by heavy-drinkers from all ages and income levels.

\section{First Cluster of Problem Drinkers}

Roughly $42 \%$ of the sample falls in this group. There are equal number of men and women in this group as well as members from all the age groups. They are distinguished by high levels of satisfaction as well as heavy reliance on the medical system. They have a higher level of trust in doctors and health service professionals as compared to members of the other cluster. This group also has the least ability to retrieve health information as well as to understand health information. Further, this group is highly worried, has high level of hopelessness and anxiety, and has less interest in life. They are also highly affected by the ill effects of heavy 
alcohol consumption such as depression and anxiety. This group is unable to understand health information and cannot survive without heavy support from health service professionals and doctors. They exhibit low levels of self-efficacy. But this group also seems to make use of the services of health care professionals the most. Hence considering all these characteristics, we can call them the 'Vulnerables'.

\section{Second Cluster of Problem Drinkers}

Cluster. 2 comprises roughly $58 \%$ of the sample. Members of this cluster are least satisfied with and less reliant on health service professionals like doctors or nurses. They are least satisfied with the health care system and generally do not rely on the health care system. They are highly confident of their ability to retrieve and understand healthcare information. They are also most confident about their health. They are neither depressed nor worried and they also do not suffer from a low interest in life. This cluster therefore includes heavy drinkers who are very confident in what they do and don't seem to be bothered about health care advice or help from health service professionals. Considering these characteristics, it may be pertinent to call them the 'Unreasonable self-believers'.

Table. 6 gives a summary of cluster profile based on the analysis of the means of health management style variables.

-Insert Table 6 here-

\section{Discussion and Implications}

This study provides unique insights into understanding how segmentation could be a useful tool for social marketing endeavours that strive to reduce excessive alcohol consumption. However, few intervention studies report the use of segmentation (Rundle-Thiele et al. 2015). In particular, past social marketing studies have not utilised health management styles as the basis of segmenting heavy drinkers. As such, this study makes a significant contribution to the social marketing literature by illustrating a novel way of targeting heavy drinkers by utilising their health management style. While health management style is per se not related to social marketing, clusters identified on the basis of health management style can provide social marketers with differentiated and targeted marketing interventions to change drinking behaviour. While some heavy drinkers might benefit from greater support from health system providers, others might benefit from uplifting marketing messages that engage them by bolstering their self-confidence and self-worth. This research provides much needed 
granularity to dig deeper into the hitherto assumed monolithic segment of excessive alcohol consumers or 'heavy drinkers'.

The findings of this study suggest that an understanding of the relationship between individual characteristics and drinking requires moving beyond simple demographics, and beyond viewing drinking as a dichotomous choice in terms of drinkers and non-drinkers. Interestingly, in contrast to previous studies on alcohol consumption (Hassan and Shiu 2007; Dietrich et al. 2015), our study findings indicate that demographic variables such as gender, age, income or educational level do not show any association with the cluster classification. This implies that the clusters are purely based on attitudes and opinions of the individuals, and these attitudes and opinions cut across demographic profiles. Hence, our findings suggest that there is a need to view excessive alcohol consumption as a more nuanced problem and part of a broader system mediated by health care access and utilization, such as health management styles and health status of individuals.

Our study demonstrates that the health management style provides a rich description of heavy drinker segments, which could have important implications for social marketers. Such an approach could provide unique insights that can be applied to better frame the social marketing interventions, which may lead to a long-term change in behaviour. The insights gained from the two clusters analysed in the study could be utilised to develop appropriate marketing programmes to cater to the requirements of each chosen segment. For example, the cluster analysis of heavy drinkers indicates several important patterns.

First, it is evident that $42 \%$ of heavy drinkers are 'vulnerables', which seems like a group that has tried to reduce their heavy drinking habits, but in vain, and consequently feel very helpless and worried. Although this segment can be expected to be the most cooperative segment, however, they still fall in the heavy drinking category possibly either due to the limited success of the social marketing interventions or due to psychological and psychosocial conditions. It clear that while this segment is heavily dependent on health care professionals, such interactions have not had any significant effect in altering their drinking behaviour. For instance, Kington (2002) found that even though there was an increase in alcohol discussions when physicians were prompted to do so, health care providers were not often enough forthcoming in giving advice and working with a patient to reduce drinking, in spite of the evidence that these methods are effective. In this context, Bradley et al. (2002) aptly point out the need for medical education to increase physician skill in alcohol problems intervention. Downstream social marketing, which operates under the assumption that unhealthy behaviours mainly result due to a lack of knowledge or an attitude that reinforces 
that behaviour, and thus can be controlled (Wymer, 2011), could be most useful in targeting such consumers. With regard to this segment, what is necessary is to offer advanced and specialised 'educational' intervention programmes as such programmes could help develop the required skills and knowledge to help reduce alcohol consumption (Rundle-Thiele et al. 2013); combining education with social marketing can be an effective approach to generate long-term change in their behaviours (Rothschild, 1999). 'Edutainment' programs, which are programs for reducing alcohol consumption that extend beyond information-only campaigns and include entertainment such as games, music, blogs and websites (see Rundle-Thiele et al. 2015) could also be utilised to improve the attitude and knowledge of the target group about alcohol consumption. For example, the 'Be Under Your Own Influence' program, an inschool communication campaign was successful in reducing alcohol consumption among younger adolescents (Slater et al., 2006). Other such examples of social marketing programs are the interactive SHAHRP program, which used a series of skillbased activities (McBride, Farringdon, Midford, Meuleners, \&Phillips, 2004) and Game On: Know Alcohol (GOKA; Rundle-Thiele et al. 2015) that was formulated to tackle the problem of drinking.

Second, the study finds that the largest percentage (58\%) of heavy drinkers have very low reliance on health care professionals and feel quite confident about solving their problems without any help from others. The existence of this segment goes to support the prevalent view about the difficulties inherent in bringing together patients and health care professionals in sustainable partnerships to reduce health problems (Renedo et al, 2015). The lack of trust in doctors as revealed by this cluster of heavy drinkers supports the findings of a previous study by Johanson et al (1998) on physician-patient interaction, which shows that physicians pay very little attention to their educational mission, giving information and advice to patients only in very vague and general terms. Accordingly, it seems that this segment - the 'unreasonable self-believers' - may not be attentive to general educational programmes or communications about such programs and may have a mental barrier towards accepting problems related to heavy drinking. This segment is, hence, one of the biggest challenges for effective social marketing efforts. Potential social marketing strategies may include targeted communication for this segment by selecting appropriate communication channels. For example, advertisements may utilise fear as the key emotional appeal to change the mindset of this particular cohort. Thus, social marketing efforts that try to change the general attitude of the individuals towards accepting help from health care professionals should be the main focus in targeting this segment. As such, social marketing for this segment may need to move beyond individual downstream to midstream and upstream 
(Donovan, 2011; Wymer, 2011) approaches, which require efforts to be focused towards environment and social influence modification (Arli et al. 2015). It may be pragmatic to look for any inherent or deep-rooted problems of this segment from the point of view of their living environment and family issues. It may also be useful to seek co-operation from the government in terms of statutory regulations to tackle the problem of excessive alcohol consumption as peer, social and environmental influences may play a key role in influencing alcohol consumption habits of this segment (Rundle-Thiele et al. 2013; Kubacki et al. 2011). For instance, strategies building positive environmental influences such as curfews, introducing legal limits, product labelling, etc., may help to a certain extent (Rundle-Thiele et al. 2013). Social marketing programs that aim at constraining the individual's voluntary behaviour could also be useful for this segment. For example, legal sanctions (such as drink driving) or other regulations (such as alcohol-free venues) could be utilised along with strict regulation of alcohol advertisements. "Upstream" approaches such as making alcohol less visible, more expensive, and harder to access (Henley et al. 2011) may also work with this segment. However, future research should try and understand the psychological, social and environmental barriers that may be preventing this segment from accepting help from health care professionals, and explore how they can be motivated to change their attitudes and drinking habits.

Overall, there are several interesting observations that arise from the study findings. First, while Cluster 1 is heavily dependent on health care professionals, such interactions have not had any significant effect in altering their drinking behaviour. There is scope for social marketing here, with public health services reaching out to this segment with informative and educational programs, including those which seek to engage this target group through entertainment such as games, music, blogs and websites, may provide an effective means to influence such a segment. ,. On the other hand, for Cluster.2, social marketing needs to support their independence and control, while maintaining their connection with health service professionals. Thus, social marketing efforts that could potentially shift Cluster. 2 members from heavy to moderate drinker category may include social marketing programs that aim to target the social determinants of health and safety as such upstream approaches may elicit desired individual behaviour, often without the individual's conscious cooperation. .. As such, it is clear that social marketing interventions aimed at different clusters presented in this research would need to vary along a continuum from prevention to promotion and maintenance, as reflected by the individual health management styles, and attitudes and inclination towards using health care support system (Evans, 2006). 
Second, the differences that exist between the two clusters of problem drinkers in terms of their reliance on health care providers supports the argument put forth by Mittler et al. (2013) that patient engagement with the health service provision is very 'dynamic in nature' and patients often advance or regress in their level of engagement in a non-linear fashion. As Cohen et al. (2007) and Cunningham and Breslin (2004) have shown in their studies, only a small percentage of heavy drinkers ever attend any educational programmes. Hence, the ultimate goal of reducing excessive alcohol consumption needs to acknowledge the complex and contextual nature of health service utilization (Gately, Rogers, and Sanders, 2007) as reflected in the two clusters identified in this study.

Overall, this study provides a relevant, measurable and effective basis for segmenting heavy drinkers based on their health management style. By identifying two clear segments of heavy drinkers, this study provides unique theoretical and practical insights, which are likely to be helpful in designing and communicating social marketing programmes that could be effectively tailored to target these different clusters of heavy drinkers.

\section{Limitations, Future Research and Conclusions}

The research is not devoid of limitations. The study is based on secondary data collected in the United States. It is also found that the clustering methodology fails to provide a clearlydefined clusters in terms of the responses provided to the health-related issues. Even though a fairly accurate division is seen to have been made, there are still a few overlapping cases. In future, studies could be extended to other contexts using primary data on global alcohol consumers. For instance, studies could be conducted to compare results in other health care contexts like the U.K where healthcare is publicly owned in order to assess the stability of the segmentation framework. Future studies could also conduct further in-depth investigations into the two segments discovered by this study. Such studies could expand on other characteristics of the two segments to discover other important behavioural and attitudinal correlates. There is also scope for conducting qualitative research to explore the reasons behind the adoption of specific health management styles by heavy drinkers in these two segments to aid the development of public policy and social marketing programmes for targeting these segments.

In conclusion, it is well established that health problems associated with excessive alcohol consumption have reached alarming levels, and excessive alcohol consumption add to the social costs and can have implications that extend beyond the individual (O'Cass and Griffin, 2015). In this context, access and utilization of health care services provides an 
interesting perspective to the heavy drinking problem as individual preferences must be reflected in the choice of treatment and decisions made (Boyce \& Lamont, 1998), which could be a reflection of different health management styles. Overall, this study demonstrates that the cluster analysis of heavy drinkers based on their health management style provides a novel and practically useful picture of heavy drinker categories. The cluster solution indicates several important patterns that can be used for developing social marketing interventions, which can be tailored to target different segments of heavy drinkers differently to trigger positive social change. The study provides an actionable perspective for future research, public policy and social marketing.

\section{References}

Andreasen, A.R. (2002), "Marketing social marketing in the social change marketplace", Journal of Public Policy and Marketing, Vol. 3, No. 1, pp. 1-13.

Arli, D., Rundle-Thiele, S., \& Lasmono, H. (2015), “Consumers' evaluation toward tobacco companies: implications for social marketing", Marketing Intelligence \& Planning, Vol. 33, No.3, pp. 276-291.

Baer, J. S. (2002) "Student factors: understanding individual variation in college drinking", Journal of Studies on Alcohol, Vol. 14, pp. 40-53.

Bandura, A. (1977), "Self-efficacy: toward a unifying theory of behavioural change." Psychological Review, Vol. 84, No.2, pp.191 -215.

Barnett, N.P., Borsari, B., Hustad, J.T., Tevyaw, T.O.L., Colby, S.M., Kahler, C.W. and Monti, P.M., (2008), "Profiles of college students mandated to alcohol intervention", Journal of Studies on Alcohol and Drugs, Vol.69, No. 5, pp. 684-694.

Benton S. L, Downey R. G, Glider P. S, Benton S. A, Shin K, Newton D. W, Arck W, and Price A. (2006), "Predicting negative drinking consequences: Examining descriptive norm perception", Journal of Studies on Alcohol, Vol.67, pp. 399-405. 
Blixen, C.E., Webster, N.J., Hund, A.J., Perzynski, A.T., Kanuch, S.W., Stoller, E.P., McCormick, R.A. and Dawson, N.V. (2008), "Communicating about alcohol consumption to nonharmful drinkers with hepatitis $\mathrm{C}$ : patient and provider perspectives”, Journal of General Internal Medicine, Vol. 23, No.8, pp.1290-1295.

Bradley, K.A, Epler A.J., and Bush K.R.(2002) “Alcohol-related discussions during general medicine appointments of male VA patients who screen positive for at-risk drinking”, Journal of General Internal Medicine, 17, p. 315-26.

Carins, J. and Sharyn Rundle-Thiele, S.R. (2013), "Eating for the better: a social marketing review (2000-2012)", Public Health Nutrition, available at: www.ncbi.nlm.nih.gov/pubmed/ 23711161 (accessed 29 December 2016).

(https://www.cdc.gov/media/releases/2015/p1015-excessive-alcohol.html).

Cohen, E, Feinn, R., Arias, A and Kranzler, H.R. (2007), “Alcohol Treatment Utilisation: Findings from National Epidemiologic Survey on Alcohol Related Conditions”, Drug and Alcohol Dependence; Vol. 86, pp. 214-221.

Cooper, M. L. (1994). Motivations for alcohol use among adolescents: Development and validation of a four-factor model. Psychological Assessment, 6(2), 117-128

Croker, H., Lucas, R. and Wardle, J. (2012), "Cluster-randomised trial to evaluate the 'change for life' mass media/social marketing campaign in the UK", BMC Public Health, Vol. 12 (404), pp.1-14.

Cunningham, J.A and Breslin, F.C. (2004), "Only One in three people with Alcohol Abuse or Dependence Ever Seek Treatment”, Additive Behaviours, Vol. 29, pp. 221-223.

Dibb, S., Stern, P. and Wensley, R. (2002), "Marketing knowledge and the value of segmentation", Marketing Intelligence \& Planning, Vol. 20 (2), pp. 113-119.

Dietrich T, Rundle-Thiele S, Leo C, Connor J. (2015) “One size (never) fits all: segment differences observed following a school-based alcohol social marketing program", Journal of School Health, Vol. 85, pp. 251-259.

DiMatteo M. R. (2004), “Variations in patients' adherence to medical recommendations: A quantitative review of 50 years of research”, Medical Care; Vol. 42, pp. 200-209.

Dolnicar, S. and B. Grun (2017) "Methods in Segmentation" Chapter in Segmentation in Social Marketing: Methods and Approaches. Editors Dietrich, T., Rundle-Thiele, S.R. and Kubacki, K. (2017). Springer, Singapore

Dolnicar, S; Grun, B and Leisch, F. (2016), "Increasing Sample size compensates for data problems in segmentation studies”, Journal of Business Research, Vol.69, pp.992-999. 
Donovan, R. (2011), “Social marketing’s mythunderstandings”, Journal of Social Marketing, Vol. 1, No. 1, pp. 8-16.

Evans W. D. (2006), "How social marketing works in health care", British Medical Journal, May 20; 332(7551): 1207-1210.

Fiscella K, Franks P, Clancy C. M, Doescher M. P and Banthin J. S. (1999), "Does scepticism towards medical care predict mortality?” Medical Care, Vol. 37, pp. 409414.

French, J. (2009), "The nature, development and contribution of social marketing to public health practice since 2004 in England", Perspectives in Public Health, Vol. 129 No. 6, pp. 262-267.

French, J. and Blair-Stevens, C. (2006), "From snake oil salesmen to trusted policy advisors: the development of a strategic approach to the application of social marketing in England", Social Marketing Quarterly, Vol. 12 No. 3, pp. 29-40.

Gately, C., Rogers, A. and Sanders, C. (2007), "Re-thinking the relationship between longterm condition self-management education and the utilisation of health services", Social Science \& Medicine, Vol. 65 No.5, pp. 934-945.

Glik, D., Prelip, M., Myerson, A., \& Eilers, K. (2008), "Fetal alcohol syndrome prevention using community-based narrowcasting campaigns", Health Promotion Practice, Vol.9, pp. 93-103.

Gray, D. M., \& Bean, B. (2011), “Can social marketing segmentation initiatives be used to increase household electricity conservation?", Journal of Nonprofit and Public Sector Marketing, Vol.23 No.3, pp. 269-305.

Hassan, L. M., \& Shiu, E. M. (2007), “Gender differences in low-risk single-occasion drinking: an application of the theory of planned behaviour", International Journal of Consumer Studies, Vol. 31 No.4, pp. 317-325.

Henley, N., Raffin, S. \& Caemmerer, B. (2011) "The application of marketing principles to a social marketing campaign", Marketing Intelligence \& Planning, Vol. 29 No. 7 pp. 697 - 706 Hogan, S. P., Perks, K. J., \& Russell-Bennett, R. (2014). Identifying the key sociocultural influences on drinking behavior in high and moderate binge-drinking countries and the public policy implications. Journal of Public Policy \& Marketing, Vol.33 No.1, pp.93107. 
Johnston L. D, O’Malley P. M, Bachman J. G and Schulenberg J. E (2005), "Monitoring the Future: National Survey Results on Drug Use, 1975-2004”, Vol. 1, NIH Publication No. 05-5727. Bethesda, MD: National Institute on Drug Abuse.

Johanson, M., Larsson, U. S., Säljö, R. and Svärdsudd, K. (1998). "Lifestyle discussion in the provision of health care. An empirical study of patient-physician interaction", Social Science \& Medicine, Vol. 47 No.1, pp.103-112.

Kington R.A. (2002), "Internal Medicine and Alcohol: Time to Move Forward”, Journal of General Internal Medicine, May; Vol.17 No.5, pp. 400-401.

Kotler (1980) Marketing Management: Analysis, Planning and Control, $4^{\text {th }}$ Edn, Englewood Cliffs: NJ: Prentice-Hall

Kubacki K., Dariusz S., and Rundle-Thiele (2011),"College binge drinking: a new approach", Journal of Consumer Marketing, Vol. 28 No.3, pp. 225 - 233

Kubacki, K., Rundle-Thiele, S., Pang, B., \& Buyucek, N. (2015), "Minimizing alcohol harm: A systematic social marketing review (2000-2014)”, Journal of Business Research, Vol. 68 No.10, pp. 2214-2222.

LaBrie, J. W., Pedersen, E. R and Tawalbeh, S. (2007), “Classifying risky-drinking college students: another look at the two-week drinker-type categorization", Journal of Studies on Alcohol and Drugs, Vol. 68 No.1, pp. 86-90.

Leeman, R. F., Kulesza, M., Stewart, D. W. and Copeland, A. L. (2012), “Cluster analysis of undergraduate drinkers based on alcohol expectancy scores", Journal of Studies on Alcohol and Drugs, Vol.73 No.2, pp. 238-249.

Masser, B.M., White, K.M., Hyde, M.K., Terry, D.J. and Robinson, N.G. (2009), "Predicting blood donation intentions and behavior among Australian blood donors: testing an extended theory of planned behavior model", Transfusion, Vol. 49 No. 2, pp. 320-329.

Millon, T., Green, C. J and Meagher, R. B. (1979), "The MBHI: A new inventory for the psychodiagnostician in medical settings", Professional Psychology, Vol.10 No.4, pp. 529-539.

Mittler, J. N., Martsolf, G. R., Telenko, S. J and Scanlon, D. P. (2013), "Making sense of consumer engagement" initiatives to improve health and health care: a conceptual framework to guide policy and practice", Milbank Quarterly, Vol.91 No.1, pp.37-77.

Moss, H. B., Kirby, S. D and Donodeo, F. (2009), "Characterizing and Reaching High-Risk Drinkers Using Audience Segmentation", Alcoholism: Clinical and Experimental Research, Vol. 33 No.8, pp. 1336-1345. 
Neighbors C, Lee C. M, Lewis M. A, Fossos N and Larimer M. E. (2007), “Are social norms the best predictor of outcomes among heavy drinking college students?", Journal of Studies on Alcohol and Drugs, Vol 68, pp. 556-565.

Nelson, T. F., Xuan, Z., Lee, H., Weitzman, E. R. and Wechsler, H. (2009), "Persistence of heavy drinking and ensuing consequences at heavy drinking colleges", Journal of Studies on Alcohol and Drugs, Vol.70 No.5, pp. 726-734.

NHS Digital (2018), "Statistics on Alcohol, England 2018” available at https://digital.nhs.uk/data-and-information/publications/statistical/statistics-on-alcohol/2018

NIAAA (2009), "What's at risk or heavy drinking", https://www.rethinkingdrinking.niaaa.nih.gov/How-much-is-too-much/Is-your-drinkingpattern-risky/Whats-At-Risk-Or-Heavy-Drinking.aspx

O'Cass, A., \& Griffin, D. (2015), "Eliciting positive social change: marketing's capacity to drive prosocial behaviours", Marketing Intelligence \& Planning, Vol. 33 No.5, pp.826843.

Paswan, A. K., Gai, L., \& Jeon, S. (2015), “Alcohol and college students: Reasons, realization and intention to quit", Journal of Business Research, Vol. 68 No.10, pp.2075-2083.

Perzynski A.T, McCormick R, Webster N. J, Blixen C. E, Kanuch S, Thomas C. L and Dawson N. V. (2011), "Psychosocial correlates of alcohol use and reduction for individuals with hepatitis C", Journal of Studies on Alcohol and Drugs,Vol.72, pp.787798.

Prochaska, J. O., \& DiClemente, C. C. (1992) "Stages of change in the modification of problem behaviors" Progress in Behavior Modification, Vol. 28, pp.183-218.

Renedo, A., Marston, C.A., Spyridonidis, D and Barlow, J. (2015), "Patient and Public Involvement in Healthcare Quality Improvement: How organizations can help patients and professionals to collaborate", Public Management Review, Vol.17 No.1, pp. 17-34, Rothschild, Michael L. ((1999) "Carrots, sticks, and promises: A conceptual framework for the management of public health and social issue behaviors." Journal of Marketing, pp. 24-37.

Rundle-Thiele, S. R., Russell-Bennett, R., Leo, C., \& Dietrich, T. (2013), "Moderating teen drinking: Combining social marketing and education", Health Education, Vol.113 No.5, pp. 392-406 
Rundle-Thiele, S., Kubacki, K., Tkaczynski, A., \& Parkinson, J. (2015), “Using two-step cluster analysis to identify homogeneous physical activity groups", Marketing Intelligence \& Planning, Vol.33 No.4, pp. 522-537.

SPSS (2001), The SPSS two-step cluster component: A scalable component to segment your customers more effectively. White paper-technical report, Chicago, pp. 1-9.

Stoller, E. P., Webster, N. J., Blixen, C. E., McCormick, R. A., Hund, A. J., Perzynski, A. T., ... Dawson, N. V. (2009). Alcohol consumption decisions among non-abusing drinkers diagnosed with hepatitis C: An exploratory sequential mixed methods study. Journal of Mixed Methods Research, Vol.3, pp. 65-86.

Sutton, E., Eborall, H. and Martin, G. (2015), "Patient Involvement in Patient Safety: Current experiences, insights from the wider literature, promising opportunities?", Public Management Review, Vol.17 No.1, pp. 72-89

UK Department of Health (2013), Reducing harmful drinking. Department of Health (available: https://www.gov.uk/government/policies/reducing-harmful-drinking accessed: 12May 2015).

Vermeire, E., Hearnshaw, H., Van Royen, P and Denekens, J. (2001), "Patient adherence to treatment: three decades of research. A comprehensive review", Journal of Clinical Pharmacy and Therapeutics, Vol.26 No.5, pp. 331-342.

Walsh, G., Hassan, L. M., Shiu, E., Andrews, J. C., \& Hastings, G. (2010), “Segmentation in social marketing: Insights from the European Union's multi-country, antismoking campaign”, European Journal of Marketing, Vol.44 No.7/8, pp.11401164.

WHO (2015). Alcohol. Fact sheet. Available: http://www.who.int/mediacentre/factsheets/ fs349/en/. (Accessed 6th Nov. 2016)

Wymer, W. (2011), “Developing more effective social marketing strategies”, Journal of Social Marketing, Vol. 1 No. 1, pp. 17-31. 
Table 1: Results of the auto-clustering process

\begin{tabular}{|l|r|r|r|r|}
\hline \multicolumn{5}{|c|}{ Auto-Clustering } \\
\hline $\begin{array}{l}\text { Number of } \\
\text { Clusters }\end{array}$ & $\begin{array}{c}\text { Schwarz's } \\
\text { Bayesian } \\
\text { Criterion (BIC) }\end{array}$ & BIC Change & \multicolumn{1}{|c|}{$\begin{array}{c}\text { Ratio of } \\
\text { BIC } \\
\text { Changes }\end{array}$} & $\begin{array}{c}\text { Ratio of } \\
\text { Distance } \\
\text { Measures }\end{array}$ \\
\hline 1 & 6378.590 & & & \\
\hline 2 & 4763.651 & -1614.939 & 1.000 & 2.672 \\
\hline 3 & 4238.821 & -524.830 & .325 & 1.248 \\
\hline 4 & 3843.701 & -395.120 & .245 & 2.189 \\
\hline 5 & 3732.158 & -111.543 & .069 & 1.641 \\
\hline 6 & 3713.766 & -18.392 & .011 & 1.063 \\
\hline 7 & 3704.014 & -9.752 & .006 & 1.034 \\
\hline 8 & 3698.703 & -5.311 & .003 & 1.081 \\
\hline 9 & 3703.358 & 4.655 & -.003 & 1.040 \\
\hline 10 & 3712.682 & 9.324 & -.006 & 1.154 \\
\hline 11 & 3737.707 & 25.025 & -.015 & 1.061 \\
\hline 12 & 3768.560 & 30.853 & -.019 & 1.085 \\
\hline 13 & 3806.916 & 38.357 & -.024 & 1.193 \\
\hline 14 & 3859.605 & 52.689 & -.033 & 1.074 \\
\hline 15 & 3917.401 & 57.796 & -.036 & 1.114 \\
\hline
\end{tabular}

athe changes are from the previous number of clusters in the table 
Table 2: Variables used for cluster analysis

\begin{tabular}{|c|c|c|c|c|c|c|c|c|}
\hline & \multicolumn{2}{|l|}{ Always } & \multicolumn{2}{|l|}{ Usually } & \multicolumn{2}{|c|}{ Sometimes } & \multicolumn{2}{|l|}{ Never } \\
\hline & Cluster.1 & Cluster.2 & Cluster.1 & Cluster.2 & Cluster.1 & Cluster.2 & Cluster.1 & Cluster.2 \\
\hline $\begin{array}{l}\text { In the past } 12 \text { months, how often did your health } \\
\text { professional: Give you the chance to ask all the health-related } \\
\text { questions you had }\end{array}$ & $13^{*}$ & 0 & 34 & 0 & 85 & 27 & 45 & 219 \\
\hline $\begin{array}{l}\text { In the past } 12 \text { months, how often did your health } \\
\text { professional: Give the attention you needed to your feelings } \\
\text { and emotions }\end{array}$ & 22 & 0 & 61 & 2 & 85 & 69 & 9 & 175 \\
\hline $\begin{array}{l}\text { In the past } 12 \text { months, how often did your health } \\
\text { professional: Involve you in decisions about your health care } \\
\text { as much as you wanted }\end{array}$ & 15 & 0 & 50 & 1 & 95 & 43 & 17 & 202 \\
\hline $\begin{array}{l}\text { In the past } 12 \text { months, how often did your health } \\
\text { professional: Make sure you understood the things you needed } \\
\text { to do to take care of your health }\end{array}$ & 7 & 0 & 33 & 1 & 116 & 15 & 21 & 230 \\
\hline $\begin{array}{l}\text { In the past } 12 \text { months, how often did your health } \\
\text { professional: Explain things in a way you could understand? }\end{array}$ & 5 & 0 & 24 & 0 & 114 & 8 & 34 & 238 \\
\hline $\begin{array}{l}\text { In the past } 12 \text { months, how often did your health } \\
\text { professional: Spend enough time with you? }\end{array}$ & 28 & 0 & 48 & 8 & 90 & 58 & 11 & 190 \\
\hline $\begin{array}{l}\text { In the past } 12 \text { months, how often did your health } \\
\text { professional: Help you deal with feelings of uncertainty about } \\
\text { your health or health care }\end{array}$ & 28 & 4 & 58 & 11 & 89 & 60 & 5 & 171 \\
\hline
\end{tabular}

*the numbers in the cells indicate the number of problem drinkers who provided this particular response to the statement and were classified into the indicated cluster. 
Table 3 Demographic Profile of the two clusters

\begin{tabular}{|l|l|l|}
\hline & Cluster.1 & Cluster.2 \\
\hline Males & $62(39.2 \%)$ & $88(39.3 \%)$ \\
\hline Females & $96(60.8 \%)$ & $136(60.7 \%)$ \\
\hline $18-34$ & $33(18.8 \%)$ & $41(16.9 \%)$ \\
\hline $35-49$ & $56(31.8 \%)$ & $52(21.4 \%)$ \\
\hline $50-64$ & $62(35.2 \%)$ & $94(38.7 \%)$ \\
\hline $65-74$ & $15(8.5 \%)$ & $35(14.4 \%)$ \\
\hline $75+$ & $10(5.7 \%)$ & $21(8.6 \%)$ \\
\hline
\end{tabular}


Table 4 Correlation of Cluster membership with 'difficulty in receiving health related information' and 'trust on sources'.

\begin{tabular}{|l|l|l|l|l|}
\hline Variable & F-value & p-value & Cluster.1 & Cluster.2 \\
\hline $\begin{array}{l}\text { The information found was hard to } \\
\text { understand }\end{array}$ & 6.82 & 0.009 & 2.93 & 3.18 \\
\hline $\begin{array}{l}\text { Overall how confident are you about } \\
\text { getting advice or information about } \\
\text { health or medical topics }\end{array}$ & 30.44 & 0.00 & 2.55 & 2.04 \\
\hline $\begin{array}{l}\text { Overall how will you rate the } \\
\text { quality of health care you received } \\
\text { in the past 12 months }\end{array}$ & 134.83 & 0.00 & 3.48 & 4.42 \\
\hline $\begin{array}{l}\text { In general how much do you trust } \\
\text { information about health from } \\
\text { Doctors }\end{array}$ & 17.77 & 0.00 & 1.55 & 1.28 \\
\hline $\begin{array}{l}\text { In general how much do you trust } \\
\text { information about health from } \\
\text { Family or friends }\end{array}$ & 7.22 & 0.04 & 2.52 & 2.33 \\
\hline
\end{tabular}

a- Measured on a four-point scale where $1=$ strongly agree $4=$ strongly disagree

b- Measured on a five-point scale where $1=$ completely confident; $5=$ not confident at all

c- Measured on a five-point scale where $1=$ excellent and $5=$ poor

d- Measured on a four-point scale where $1=$ a lot and $4=$ not at all 
Table 5 Correlation of Cluster membership with 'Health status'

\begin{tabular}{|l|l|l|l|l|}
\hline & F-Value & p-value & Cluster.1 mean & Cluster.2 mean \\
\hline $\begin{array}{l}\text { Over the past 2 weeks, how often have } \\
\text { you experienced: Little interest or } \\
\text { pleasure in doing things? }\end{array}$ & 10.46 & .000 & 3.14 & 3.43 \\
\hline $\begin{array}{l}\text { Over the past 2 weeks, how often have } \\
\text { you experienced: Feeling down, } \\
\text { depressed or hopeless? }\end{array}$ & 5.83 & .016 & 3.21 & 3.42 \\
\hline $\begin{array}{l}\text { Over the past 2 weeks, how often have } \\
\text { you experienced: Feeling nervous, } \\
\text { anxious or on edge? }\end{array}$ & 4.39 & .037 & 3.15 & 3.34 \\
\hline $\begin{array}{l}\text { Over the past 2 weeks, how often have } \\
\text { you experienced: Not being able to stop } \\
\text { or control worrying? }\end{array}$ & 5.26 & .022 & 3.20 & 3.40 \\
\hline
\end{tabular}

$\mathrm{a}-$ measured on a four point scale where $1=$ nearly every day; $2=$ more than half the days; 3

$=$ several days and $4=$ not at all 
Table.6 Summary of cluster characteristics

\begin{tabular}{|l|l|l|}
\hline & $\begin{array}{l}\text { Cluster.1 } \\
\text { 'Vulnerables' }\end{array}$ & $\begin{array}{l}\text { Cluster.2 } \\
\text { 'Unreasonable } \\
\text { self -believers' }\end{array}$ \\
\hline $\begin{array}{l}\text { Health Management Style: } \\
\text { a) Reliance on doctors or other health service } \\
\text { professionals }\end{array}$ & High & Low \\
\hline b) Trust in doctors & Low & Low \\
\hline Satisfaction with health care received & High & Low \\
\hline Self- efficacy & Low & High \\
\hline $\begin{array}{l}\text { Health Status } \\
\text { (Depression/worry/hopelessness) }\end{array}$ & High & Low \\
\hline
\end{tabular}

